\title{
Severe Rhabdomyolysis and Acute Renal Failure Treated by Continuous Venovenous Hemodiafiltration in a Child with Diabetic Ketoacidosis
}

\author{
Ayhan Yaman॰
}

\begin{abstract}
Diabetic ketoacidosis (DKA) is the most serious hyperglycemic emergency in patients with type I diabetes mellitus and is associated with significant morbidity and mortality. DKA may be a life-threatening condition due to severe clinical and biological impairments and treatment-associated complications [cerebral edema, acute respiratory failure, acute renal failure (ARF), hypokalemia, hypophosphatemia]. The development of ARF with rhabdomyolysis is a rare but potentially lethal disorder in children with DKA with an estimated mortality of about $50 \%$. Continuous renal replacement therapy is commonly used in intensive care units to provide renal replacement and fluid management. We successfully treated a 13-year-old boy with continuous venovenous hemodiafiltration, who had been diagnosed with severe DKA, complicated with hypophosphatemiainduced acute respiratory failure, rhabdomyolysis and ARF, persistent acidosis, and coma.

Keywords: Acute renal failure, Continuous venovenous hemodiafiltration, Critically ill, Diabetic ketoacidosis, Hypophosphatemia, Intensive care unit, Mechanical ventilation.

Indian Journal of Critical Care Medicine (2022): 10.5005/jp-journals-10071-24093
\end{abstract}

\section{INTRODUCTION}

The occurrence of diabetic ketoacidosis (DKA) in pediatric patients with type 1 diabetes mellitus (T1DM) has remained at high rates. It bears severe risk of life-threatening manifestations due to cerebral edema. ${ }^{1}$ While cerebral edema is one of the key complications in the occurrence of DKA, there exist some other potential complications that can cause DKA. These complications include hypercoagulability, rhabdomyolysis, thrombosis, mucormycosis, hypophosphatemia, hypokalemia, and acute renal failure (ARF). Among these complications, rhabdomyolysis with ARF disorder is rarely seen in pediatric DKA patients, but its mortality rate is quite high. ${ }^{2,3}$ Therefore, it is significant to diagnose the ARF in early phases and start the treatment with continuous renal replacement therapy (CRRT). We treated a 13-year-old boy by continuous venovenous hemodialysis, who had been diagnosed with severe DKA with associated hypophosphatemia-induced acute respiratory failure, rhabdomyolysis, and ARF.

\section{Case Description}

A 13-year-old patient admitted to the pediatric intensive care unit (PICU) with increased respiratory distress and decreased consciousness. The parents reported that he had polyuria, polydipsia, diarrhea, vomiting, and abdominal pain and had lost $5 \mathrm{~kg}$ in weight in the last 2 weeks. He had vomited continuously the day before admission. At presentation, he was lethargic and severely dehydrated. Glasgow Coma Scale (GCS) was 9, respiratory rate was $44 /$ minute, heart rate was $146 /$ minute, and blood pressure was $112 / 65 \mathrm{~mm} \mathrm{Hg}$. Respiratory examination was normal apart from tachypnea. His weight was $55 \mathrm{~kg}$ (0.19 SDS) and height was $147 \mathrm{~cm}$ (-1.82 SDS). Parents were first degree cousins.

Laboratory results are shown in Table 1. He was started on $0.9 \%$ saline infusion immediately at a rate of $20 \mathrm{cc} / \mathrm{kg} / \mathrm{hour}$, and regular insulin was started at a dose of $0.1 \mathrm{unit} / \mathrm{kg} / \mathrm{hour}$ after 1-hour saline infusion. He was considered to have a fluid deficit
Pediatric Intensive Care Unit, Istinye University, Bahcesehir Liv Hospital, Istanbul, Turkey

Corresponding Author: Ayhan Yaman, Pediatric Intensive Care Unit, Istinye University, Bahcesehir Liv Hospital, Istanbul, Turkey, Phone: +02129794000, e-mail: dryamanayhan@yahoo.com.tr

How to cite this article: Yaman A. Severe Rhabdomyolysis and Acute Renal Failure Treated by Continuous Venovenous Hemodiafiltration in a Child with Diabetic Ketoacidosis. Indian J Crit Care Med 2022;26(1): 136-138.

Source of support: Nil

Conflict of interest: None

of $10 \%$, and maintenance and deficit fluid were calculated as $3,500 \mathrm{~mL} / \mathrm{m}^{2} /$ day and administered with $0.45 \%$ saline with $\mathrm{KCL}$ added at $40 \mathrm{mmol} / \mathrm{L}$. As serum $\mathrm{HCO}_{3}$ was persistently low (less than $5 \mathrm{mmol} / \mathrm{L}$ ), he was given $1 \mathrm{mEq} / \mathrm{kg}$ of $\mathrm{NaHCO}_{3}$ in 2 hours after rehydration therapy. Serum $\mathrm{P}$ was $0.77 \mathrm{mg} / \mathrm{dL}$ at the 12th hour of treatment, and $\mathrm{KPO}_{4}$ was added to the IV fluid as half of the total potassium content. Blood glucose was not dropping to the desired amount of $50-75 \mathrm{mg} / \mathrm{dL}$, so the intravenous route of insulin and insulin dilution were checked, and a fresh preparation of insulin was used and changed every 4 hours. The insulin dose was increased gradually to $0.2 \mathrm{unit} / \mathrm{kg} / \mathrm{hour}$. In the follow-up, the patient's clinical and neurological condition (lethargic, abnormal verbal response to pain) and blood gas analysis did not improve. He was suspected to have cerebral edema at the 12th hour of treatment, so hypertonic saline was administered at $5 \mathrm{cc} / \mathrm{kg}$ in 1 hour, serum fluid rate was decreased to two thirds, and cranial computerized tomography analysis was undertaken revealing no cerebral edema or any organic lesion. In the meantime, the patient had respiratory arrest requiring intubation which was suggested secondary to hypophosphatemia. Therefore, $\mathrm{KCL}$ and $\mathrm{KPO}_{4}$ were increased gradually to a total of $100 \mathrm{mmol} / \mathrm{L}$. He was mechanically ventilated. Despite a reduction 
DKA and Hemodiafiltration

Table 1: Patient laboratory data pre- and post-CVVHDF due to acute renal failure and rhabdomyolysis

\begin{tabular}{|c|c|c|c|c|c|c|}
\hline Laboratory parameters & $\begin{array}{c}\text { Values at PICU } \\
\text { admission }\end{array}$ & $\begin{array}{c}\text { 12th hour of } \\
\text { PICU admission }\end{array}$ & $\begin{array}{c}\text { 36th hour of PICU } \\
\text { admission }\end{array}$ & $\begin{array}{c}\text { Second hour of } \\
\text { CVVHDF }\end{array}$ & $\begin{array}{l}\text { 4th hour of } \\
\text { CVVHDF }\end{array}$ & $\begin{array}{c}\text { 12th hour of } \\
\text { CVVHDF }\end{array}$ \\
\hline $\mathrm{pH}$ & 6.97 & 7.08 & 7.17 & 7.31 & 7.39 & 7.42 \\
\hline $\mathrm{HCO}_{3}(\mathrm{mmol} / \mathrm{L})$ & 3 & 6.9 & 8.3 & 11.5 & 13 & 16.4 \\
\hline $\mathrm{PCO}_{2}(\mathrm{~mm} \mathrm{Hg})$ & 13 & 20 & 23 & 25 & 28 & 33 \\
\hline Glucose (mg/dL) & 605 & 445 & 375 & & 326 & 331 \\
\hline BUN (mg/dL) & 11.7 & 26 & 29 & & 20 & 12 \\
\hline $\mathrm{Cr}(\mathrm{mmol} / \mathrm{L})$ & 1.13 & 2.46 & 2.67 & & 1.83 & 1.21 \\
\hline $\mathrm{Na}(\mathrm{mEq} / \mathrm{dL})$ & 137 & 140 & 154 & & 150 & 140 \\
\hline $\mathrm{K}(\mathrm{mEq} / \mathrm{dL})$ & 2.38 & 1.76 & 2.54 & & 3.22 & 4.63 \\
\hline $\mathrm{Ca}(\mathrm{mg} / \mathrm{dL})$ & 11.78 & 12.53 & 10.44 & & 10.3 & 8.23 \\
\hline Uric acid (mg/dL) & 3.36 & 5.84 & 4.28 & & 3.28 & 1.34 \\
\hline$P(m g / d L)$ & 1.4 & 0.77 & 0.94 & & 1.22 & 2.30 \\
\hline $\mathrm{Mg}(\mathrm{mg} / \mathrm{dL})$ & 2.74 & 2.73 & 2.40 & & 1.78 & 2.88 \\
\hline $\mathrm{CPK}(\mathrm{ng} / \mathrm{mL})$ & 7456 & 1484 & 1425 & & 1109 & 931 \\
\hline Amylase (U/L) & 50 & 233 & 424 & & 308 & 105 \\
\hline
\end{tabular}

$\mathrm{PICU}$, pediatric intensive care unit; $\mathrm{CVVHD}$, continuous venovenous hemodiafiltration; $\mathrm{PCO}_{2}$, partial pressure of carbon dioxide; $\mathrm{HCO}_{3}$, bicarbonate; $\mathrm{Cr}$, creatinine; $\mathrm{P}$, phosphorus; $\mathrm{Mg}$, magnesium; BUN, blood urea nitrogen; $\mathrm{Ca}$, calcium; $\mathrm{CPK}$, creatinine phosphokinase; $\mathrm{K}$, potassium; $\mathrm{Na}$, sodium

in the rate of fluid administration for 6 hours and hypertonic saline infusion, the patient's neurologic status did not improve (GCS) was 5 and no response to pain), and clinical signs of dehydration were still apparent. We increased the total fluid amount to the calculated level. In the course of treatment, the insulin infusion rate was between 0.1 and $0.2 \mathrm{unit} / \mathrm{kg} / \mathrm{hour}$, while IV fluid was maintained at $0.45 \%$ saline concentration. Nevertheless, blood $\mathrm{pH}$ and $\mathrm{HCO}_{3}$ did not improve at the expected rate. At the 36th hour of treatment, the patient was on mechanical ventilation in the PICU. He also had ARF and rhabdomyolysis (creatinine phosphokinase level was 7,456 at PICU admission), serum blood $\mathrm{pH}$ was 7.17, and $\mathrm{HCO}_{3}$ was $8.3 \mathrm{mmol} / \mathrm{L}$, so we decided to start continuous venovenous hemodiafiltration (CVVHDF).

We inserted a $11.5 \mathrm{Fr}, 16 \mathrm{~cm}$ dual lumen hemodialysis catheter (Covidien Ilc, Mansfield, USA) into the right subclavian vein. CVVHDF was started 36 hours after admission to the PICU. CVVHDF was administered using a hemofilter M100 extracorporeal circuit (Gambro-Prismaflex, lundia AB, Sweden). The circuit was primed with $150 \mathrm{~mL}$ of $5 \%$ albumin. The blood-pump flow rate was $150 \mathrm{~mL} /$ minute ( $3 \mathrm{~mL} / \mathrm{kg} / \mathrm{minute}$ ). Dialysate fluid rate was $1100 \mathrm{~mL} / \mathrm{hour}$ (20mL/kg/hour, DIALISAN ${ }^{\mathrm{Tm}}$; Na $140 \mathrm{mmol} / \mathrm{L}, \mathrm{K} 2.0 \mathrm{mmol} / \mathrm{L}, \mathrm{Ca}$ $\left.1.75 \mathrm{mmol} / \mathrm{L}, \mathrm{Mg} 0.5 \mathrm{mmol} / \mathrm{L}, \mathrm{HCO}_{3} 32 \mathrm{mmol} / \mathrm{L}\right)$. Replacement fluid rate was $1,800 \mathrm{~mL} /$ hour $\left(2,000 \mathrm{~mL} / \mathrm{m}^{2} / 1.73 /\right.$ hour-his body surface area was $1.56 \mathrm{~m}^{2}$ ). Net ultrafiltration rate was $110 \mathrm{~mL} /$ hour. Heparin was used to achieve anticoagulation of the extracorporeal circuit. During CVVHDF, blood gases were measured at 2 hour intervals. The patient was restored to consciousness in the second hour of CVVHDF, and the $\mathrm{pH}$ of his blood gases was measured as 7.31. His acidosis recovered completely in the 4th hour of CVVHDF. The patient's serum pH level under CVVHDF is shown in Figure 1. Because the patient was spontaneously breathing and regained his consciousness, he was extubated in the 4th hour of CVVHDF. CVVHDF was terminated 12 hours after initiation when the renal function returned to normal. There was no complication during CVVHDF. The patient was transferred to the pediatric endocrinology service on the 4th day of treatment in the PICU, and he was discharged from the hospital on the 9 th day of the hospitalization.

\section{Discussion}

DKA is the most severe hyperglycemic emergency in pediatric patients with T1DM and is associated with significant morbidity and mortality. ${ }^{4}$ DKA occurs due to lack of absolute insulin. Triad of uncontrolled hyperglycemia, metabolic acidosis, and high ketone body concentration is the manifestation of DKA. ${ }^{5}$ DKA might be a life-threatening case because of severe clinical and biological impairment and treatment-associated complications such as cerebral edema, acute respiratory failure and ARF. However, mortality rate is low, and death is generally related to the precipitating factor. ${ }^{6-9}$ Our patient was a very complicated case. He had severe DKA (serum $\mathrm{pH}<7, \mathrm{HCO}_{3}<5 \mathrm{mmol} / \mathrm{L}$, hypocarbia, long duration of symptoms before admission to the hospital, and depressed level of consciousness). During treatment, we also were faced with some complications: acute respiratory failure, hypophosphatemia, hypokalemia, persistent acidosis, and rhabdomyolysis with ARF.

Persistent acidosis is described as a bicarbonate value $<10 \mathrm{mmol} / \mathrm{L}$ after 8-10 hours of treatment. It usually stems from inadequate insulin effects. Therefore, insulin route and dilution should be checked in this condition, and insulin should be changed to a fresh dose. ${ }^{10}$ We could not determine why we had not achieved the expected improvement in acidosis with insulin and fluid treatment. The patient was severely dehydrated with prolonged symptoms 4 days since the start of symptoms to hospital admission and severe vomiting before the day of admission. Severe acidosis, severe dehydration and impaired tissue perfusion, and prolonged duration of symptoms might have had a negative impact on treatment and complicated the case. We increased the insulin dosage to $0.2 \mathrm{unit} / \mathrm{kg} / \mathrm{hour}$, suggesting probable insulin resistance. 


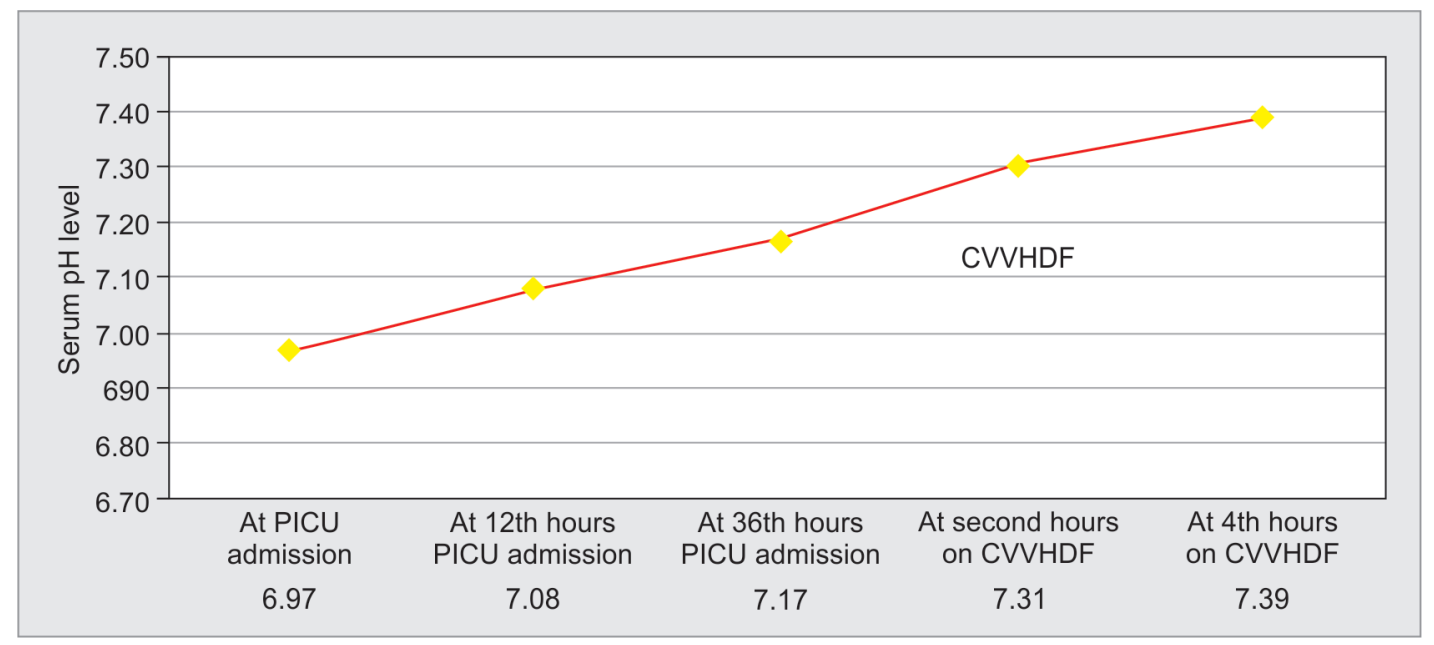

Fig. 1: Patient serum pH levels under CVVHDF

Severe hypophosphatemia may occur due to prolonged profound ketoacidosis and large dose of insulin infusions. To counter the acidemia-induced inhibition of phosphate proximal tubular reabsorption, urinary phosphate excretion is increased. As a result, the severe hypophosphatemia can cause rhabdomyolysis and cardiomyopathy. ${ }^{11,12}$ Hence, detecting changes in serum phosphate levels early in DKA is very essential although phosphate is not routinely used in DKA management. We suggest that acute respiratory failure in our patient might be secondary to hypophosphatemia, and persistent metabolic acidosis also might have had a negative impact on respiratory functions.

Renal replacement therapy is rarely required in ARF, which is a complication of DKA in pediatric patients. ${ }^{2,13,14}$ Hypovolemia and hypotension are the most probable factors that cause ARF. DKA has been often linked with the severe dehydration. However, ARF is surprisingly not seen in such cases.

The vasoconstrictor and sodium-retaining hormones (renin and aldosterone) are increased, and atrial natriuretic peptide is suppressed in order to counteract the hypovolemia. ${ }^{2}$ In a previous case, ${ }^{13}$ CVVHDF was performed on an adult patient with DKA who developed ARF due to hypovolemia and hypotension. In this case, ${ }^{13}$ there were no hypophosphatemia and rhabdomyolysis. However, in our case, ARF developed due to low P and rhabdomyolysis.

CRRT, a continuous method of blood purification, is commonly used in PICU for renal replacement and fluid management. Although our patient had enough fluid and insulin treatment, because of the resistant DKA, electrolyte abnormalities, rhabdomyolysis, and ARF, we thought the patient could benefit from CRRT. We decided to do the CVVHDF as a lifesaving treatment to the patient in a very critical state. The patient's acidosis resolved in the 4th hour of CRRT. His encephalopathy became normal, and he was restored to consciousness. Subsequently, the patient was spontaneously extubated. There are quite little data in the literature about CRRT in a DKA patient.

In conclusion, we have seen that metabolic and electrolyte abnormalities of severe DKA can rapidly become normal with CRRT, and CRRT can be considered as a treatment option for patients with severe DKA that can become complicated with ARF.

\section{ORCID}

\section{Ayhan Yaman $\odot$ https://orcid.org/0000-0002-5651-1286}

\section{References}

1. Rosenbloom AL. Hyperglycemic crises and their complications in children. J Pediatr Endocrinol Metab 2007;20(1):5-18. DOI: 10.1515/ jpem.2007.20.1.5.

2. Murdoch IA, Pryor D, Haycock GB, Cameron SJ. Acute renal failure complicating diabetic ketoacidosis. Acta Paediatr 1993;82(5):498-500. DOI: 10.1111/j.1651-2227.1993.tb12734.x.

3. Woodrow G, Brownjohn AM, Turney JH. Acute renal failure in patients with type 1 diabetes mellitus. Postgrad Med J 1994;70(821):192-194. DOI: 10.1136/pgmj.70.821.192.

4. Kitabchi AE, Umpierrez GE, Fisher JN, Murphy MB, Stentz FB. Thirty years of personal experience in hyperglycaemic crises: diabetic ketoacidosis and hyperglycaemic hyperosmolar state. J Clin Endocrinol Metab 2008;93(5):1541-1552.

5. Lombardo F, Maggini M, Gruden G, Bruno G. Temporal trend in hospitalizations for acute diabetic complications: a nationwide study, Italy, 2001-2010. PLoS One 2013;8(5):63675. DOI: 10.1371/journal. pone. 0063675 .

6. Wagner A, Risse A, Brill HL, Wienhausen-Wilke V, Rottmann M, Sondern K, et al. Therapy of severe diabetic ketoacidosis. Zeromortality under very-low-dose insulin application. Diabetes Care 1999;22(5):674-677. DOI: 10.2337/diacare.22.5.674.

7. Ezeani I, Eregie A, Ogedengbe O. Treatment outcome and prognostic indices in patients with hyperglycemic emergencies. Diabetes Metab Syndr Obes 2013;6:303-307. DOI: 10.2147/DMSO.S44477.

8. Efstathiou SP, Tsiakou AG, Tsioulos DI, Zacharos ID, Mitromaras AG, Mastorantonakis SE, et al. A mortality prediction model in diabetic ketoacidosis. Clin Endocrinol 2002;57(5):595-601. DOI: 10.1046/j.13652265.2002.01636.x.

9. Kitabchi AE, Umpierrez GE, Miles JM, Fisher JN. Hyperglycemic crises in adult patients with diabetes. Diabetes Care 2009;32(7):1335-1343. DOI: $10.2337 / \mathrm{dc} 09-9032$.

10. Rosenbloom AL. The management of diabetic ketoacidosis in children. Diabetes Ther 2010;1(2):103-120. DOI: 10.1007/s13300-010-0008-2.

11. Al-Matrafi J, Vethamuthu J, Feber J. Severe acute renal failure in a patient with diabetic ketoacidosis. Saudi J Kidney Dis Transpl 2009;20(5):831-834. PMID: 19736483.

12. Liu PY, Jeng CY. Severe hypophosphatemia in a patient with diabetic ketoacidosis and acute respiratory failure. J Chin Med Assoc 2004;67(7):355-359. PMID: 15510933.

13. Kawata H, Inui D, Ohto J, Miki T, Suzue A, Fukuta $Y$, et al. The use of continuous hemodiafiltration in a patient with diabetic ketoacidosis. J Anesth 2006;20(2):129-131. DOI: 10.1007/s00540-005-0385-2.

14. Yue RZ, Zhang L, Liu F, Fu P. Continuous blood purification therapy on 16 patients with diabetic ketoacidosis and acute kidney injury. Sichuan Da Xue Xue Bao Yi Xue Ban 2012;43(3):434-437. PMID: 22812253. 